\title{
The Contribution of Amateur Astronomers to Cometary Observation
}

\author{
André Heck \\ Centre de Données Stellaires, Observatoire Astronomique, 11 rue de l'Université, \\ F-67000 Strasbourg, France
}

Most professional astronomers do not conduct specific comet-discovery programmes and a new comet is, in general, an intrusion into an observational programme, although one that does, of course, receive all the attention it deserves. Comet discoveries are by-products of professional work. This may also be the case with some amateurs (G.E. Alcock discovered his fifth comet while looking for novae). Most amateur discoveries are the result of active and systematic work. Over the period 1951-70, on average 9 comets per year were discovered by amateurs.

The time spent scanning the sky before discovering a comet is typically hundreds of hours. The times of W. Bradfield between his first comets were 260, 306, 145 and 106 hours. Astronomers at Skalnaté Pleso discovered eight comets in six years, averaging one comet for 206 hours of searching. R.D. Austin and R. Meier spent 151 and 105 hours, respectively, between discoveries. These figures are only indicators, because many other factors (including luck) play a part. Alcock's two comets in six days is quite exceptional.

It is essential that any possible discovery should be carefully checked and repeated at least an hour, or preferably a day, later, so that any motion may be apparent. Photographic observers should interrupt their exposures asymmetrically in order to show the direction of motion. A positive finding should be confirmed by another observer before announcement. The IAU Circulars should be checked, if necessary by contacting a professional institute (for useful addresses see Heck \& Manfroid, 1986, 1987). The Central Bureau for Astronomical Telegrams may then be informed.

In recent decades there has been less and less professional astrometry of comets. The Central Bureau therefore welcomes accurate measurements and reductions from amateurs.

At various times there have been prizes for comet discoveries, but there is none at present for European amateurs as there is, for example, in the U.S.A. Can no society or company be encouraged to set up such a prize for Old-World astronomers? It would be an excellent incentive to European amateurs.

\section{References}

Heck, A.: L'Astronomie, 88, 318 (1974)

Heck, A.: Ciel et Terre, 101, 115 (1975)

Heck, A., Manfroid, J.: International Directory of Professional Astronomical Institutions - IDPAI 1987, (1st edn), CDS Spec. Publ. 9 (1986)

Heck, A., Manfroid, J.: International Directory of Astronomical Associations and Societies - IDAAS 1988, (7th edn), CDS Spec. Publ. 10 (1987) 